\title{
PELUANG DAN TANTANGAN MEWUJUDKAN DESA BERSIH NARKOBA DI KABUPATEN BADUNG
}

\author{
Made Agus Sugianto \\ Badan Penelitian dan Pengembangan Kabupaten Badung \\ agussugianto146@gmail.com
}

(Diterima: April 2021; Disetujui: Agustus 2021)

\begin{abstract}
This study aims to determine the supporting and inhibiting factors of efforts to prevent the eradication of drug abuse and illicit drug trafficking. The design of this study was a Desk Study that was conducted from September to October 2019. Descriptive data analysis was sourced from the report on the Prevention of Abuse and Illicit Drug Trafficking (P4GN) program in Badung Regency. Badung Regency is the area most prone to drugs because 34 drug cases have been found. These cases are spread across 6 sub-districts, namely Kuta, South Kuta, North Kuta, Mengwi, and Abiansemal sub-districts. Drug addicts are mostly found among private workers and employers, with an age range between 21 and 30 years. There are opportunities such as Pararem to prevent drug eradication. integrated educational curriculum with prevention programs to eradicate drug abuse and trafficking and the availability of comprehensive health services for drug addicts in Badung Regency. The challenges faced are a large number of nightclubs for drug trafficking and the emergence of customary stigma and sanctions for drug addicts. Therefore, it is necessary to carry out regular raids on night entertainment venues by the National Narcotics Agency and related agencies to limit drug trafficking.
\end{abstract}

Keywords: badung regency, narcotics, traditional village.

Abstraksi. Penelitian ini bertujuan untuk melihat faktor pendukung dan penghambat upaya pencegahan pemberantasan penyalahgunaan dan peredaran gelap narkoba. Desain penelitian ini adalah studi literatur yang dilaksanakan pada bulan September sampai dengan Oktober 2019. Analisis data secara deskriptif yang bersumber dari laporan program Pencegahan Pemberantasan Penyalahgunaan dan Peredaran Gelap Narkoba (P4GN) di Kabupaten Badung. Kabupaten Badung merupakan daerah yang paling rawan narkoba karena sudah ditemukan sebanyak 34 kasus narkoba, kasus ini tersebar di kecamatan 6 kecamatan yaitu kecamatan Kuta, Kuta Selatan, Kuta Utara, Mengwi dan Abiansemal. Pecandu narkoba paling banyak ditemukan pada pekerja swasta dan pengusaha, dengan kisaran umur antara 21 sampai dengan 30 tahun. Adanya peluang seperti Pararem pencegahan pemberantasan narkoba, terintegrasinya kurikulum pendidikan dengan program pencegahan pemberantasan penyalahgunaan dan peredaran gelap narkoba serta tersedianya layanan kesehatan paripurna bagi pecandu narkoba di Kabupaten Badung. Tantangan yang dihadapi adalah banyaknya tempat hiburan malam sebagai tempat peredaran narkoba dan munculnya stigma dan sangsi adat bagi pecandu narkoba, maka perlu melakukan razia secara teratur pada tempat-tempat hiburan malam oleh BNN dan instansi terkait guna membatasi peredaran narkoba.

Kata Kunci: desa adat, kabupaten badung, narkoba.

\section{PENDAHULUAN}

Indonesia saat ini dalam keadaan darurat narkoba dan sedang berperang keras melawan narkoba. Hasil survei Badan Narkotika Nasional (BNN) menunjukan bahwa laju prevalensi Narkoba meningkat sebanyak $0,33 \%$ dari prevalensi 2,10 pada Tahun 2018 menjadi 1,77 pada tahun 2017. Demikian pula hasil survei prevalensi penyalahgunaan narkoba di Provinsi Bali 
tahun 2018 menunjukan bahwa dari 31.178 orang pekerja yang terpapar narkoba sebanyak 13.095 orang (42\%) menyatakan teratur memakai narkoba, dan di kalangan pelajar dari 5.318 orang yang terpapar narkoba sebanyak 533 orang (10\%) mengaku sebagai pecandu (Suastawa, 2019).

Pada tahun 2018 ditemukan sebanyak 34 kasus narkoba di Kabupaten Badung. Kasus ini tersebar di 5 kecamatan, yaitu kecamatan Kuta, Kuta Selatan, Kuta Utara, Mengwi dan Abiansemal. Pecandu narkoba paling banyak ditemukan pada pekerja swasta dan pengusaha, dengan kisaran umur antara 21 sampai dengan 30 tahun.

Salah satu misi Pemerintah Kabupaten Badung yang tertuang dalam RPJMD Semesta Berencana adalah memperkuat daya saing daerah melalui peningkatan mutu sumber daya manusia dan infrastruktur wilayah. Upaya peningkatan kualitas sumber daya manusia ditujukan pada pengembangan kualitas sumber daya manusia secara komprehensif meliputi aspek kepribadian dan sikap mental, penguasaan ilmu dan teknologi, serta profesionalisme dan kompetensi. Untuk mendukung hal tersebut, maka Pemerintah Kabupaten Badung bersama DPRD Kabupaten Badung menetapkan Peraturan Daerah Kabupaten Badung Nomor 24 Tahun 2013 Tentang Pengelolaan Rumah Kos, pada pasal 11 (2) dinyatakan bahwa setiap penghuni dilarang menggunakan dan atau mengedarkan narkotika, psikotropika, zat aditif lainnya (napza) dan minuman keras (miras) (Perda Kab. Badung Nomor 24 Tahun 2013).

Pemerintah Kabupaten Badung bekerjasama Badan Narkotika Nasional Kabupaten Badung serta semua elemen masyarakat berkomitmen untuk mencegah dan memberantas narkoba di seluruh wilayah Kabupaten Badung. Demikian pula
Pemerintah Kota Tanggerang Selatan menerapkan beberapa upaya untuk mengurangi peredaran Narkoba seperti pemasangan 100 kamera CCTV di tempattempat strategis dan rawan kejahatan serta bekerja sama dengan BNN dan Kwartir Cabang Gerakan Pramuka dan membentuk Satuan Karya Pramuka (SAKA) Anti Narkoba sebagai wadah bagi generasi muda (pelajar Pramuka) untuk ikut andil dalam program pencegahan penyalahgunaan Narkotika (Manurung., Heliany., 2019).

Pengalaman di beberapa daerah menunjukkan bahwa pencegahan penyalahgunaan narkoba yang efektif memerlukan peranan aktif dari segenap lapisan masyarakat. Termasuk di dalamnya orang tua, guru, tokoh masyarakat dan agama, kelompok remaja, dan warga lainnya. Ini berarti bahwa pemberdayaan masyarakat memang sangat diperlukan agar bisa mengatasi masalah narkoba (Padmohoedojo, 2014). Hal ini sejalan dengan hasil penelitian di Surabaya menunjukan bahwa masyarakat memiliki peran penting dalam pencegahan penyalahguna narkoba. Masyarakat sudah mulai merespon secara positif dan melakukan peran aktif dalam pencegahan penyalahguna narkoba. Terbentuknya konselor sebaya, kader pemuda anti narkoba, peran orang tua, peran guru BK sudah mulai berjalan dengan baik. Pemerintah hanya melakukan pendampingan yang inten agar peran tersebut dilaksanakan oleh masyarakat secara keseluruhan (Pina., Soedirham, 2015).

Pada tanggal 15 Nopember 2018, Kepala BNN RI Komjen Pol Heru Winarko meluncuran program Desa Bersih Narkoba (Bersinar) pada beberapa kabupaten/kota di Provinsi Bali termasuk di Kabupaten Badung. Pembentukan desa bersih narkoba bertujuan untuk memerangi peredaran dan 
penyalahgunaan narkotika dan obat terlarang lainnya. Desa bersih narkoba dibentuk untuk membangun komunitas antinarkoba, sehingga ada perlawanan kepada bandar dan pengedar narkoba (Agus, 2019).

Kabupaten Badung memiliki banyak potensi dan sumber daya untuk mewujudkan desa bersih narkoba di Kabupaten Badung. Sumber daya tersebut meliputi peraturan Daerah, SDM yang berkualitas serta adanya lembaga adat yang saling terintegrasi dengan lembaga perangkat daerah pada Pemerintahan Kabupaten Badung. Dibalik potensi tersebut, tidak bisa dipungkiri pula bahwa Provinsi Bali khususnya Kabupaten Badung merupakan pangsa pasar yang besar bagi perdagangan narkoba karena banyaknya permintaan akibat tingginya kunjungan wisatawan.

Upaya pencegahan dan pemberantasan penyalahgunaan serta peredaran gelap narkoba harus lebih banyak melibatkan peran serta masyarakat, keterlibatan masyarakat disini merupakan modal sosial. Modal sosial ini penting dalam menunjang keberhasilan program Pencegahan Pemberantasan Penyalahgunaan dan Peredaran Gelap Narkoba (P4GN) di Kabupaten Badung (Iskan, Dahlan, 2019).

\section{METODE PENELITIAN}

Penelitian ini adalah penelitian deskriptif analitik dengan desain Desk Study, dimana penelitian ini menganalisis data menggunakan data sekunder yang ada. Penelitian ini dilaksanakan di Kabupaten Badung selama dua bulan yaitu dari bulan September sampai dengan Oktober 2019. Data penelitian ini bersumber dari laporan Pencegahan Penyalahgunaan dan Peredaran Gelap Narkoba (P4GN) di Kabupaten Badung dan seminar nasional tentang narkoba di Provinsi Bali.

\section{HASIL DAN PEMBAHASAN}

Data Profil Dinas Pariwisata Kabupaten Badung menunjukan peningkatan kunjungan wisatawan setiap tahun ke Kabupaten Badung seperti terlihat pada gambar di bawah ini.

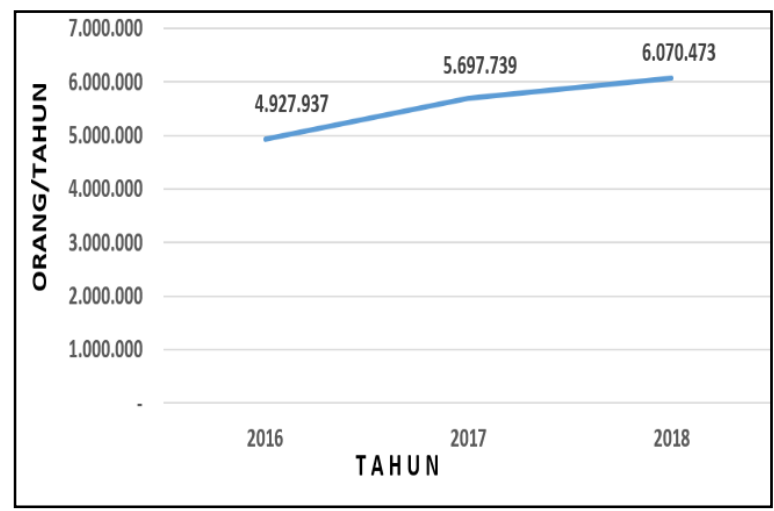

Gambar 1. Jumlah kunjungan wisatawan di Kab. Badung Tahun 2016 s.d 2018 Sumber: Diolah dari data Profil Dinas Pariwisata Kabupaten Badung, 2018

Kehadiran industri pariwisata selain membawa dampak positif terhadap peningkatan perekonomian masyarat, juga membawa membawa pengaruh negatif terhadap kehidupan sosial penduduk lokal. Pada perilaku masyarakat, khususnya pola gaya hidup, terlihat bahwa terjadi pergeseran akibat kehadiran wisatawan/pendatang dan kegiatan pariwisata. Selain itu, juga timbul perilaku menyimpang seperti tindak kriminalitas, prostitusi, dan penggunaan narkoba yang umumnya terjadi saat musim puncak kunjungan wisatawan (Dhalyana, Dini, dkk. 2013). Dari ketiga permasalahan di atas, masalah penyalahgunaan narkoba adalah yang paling sulit untuk diatasi karena sejumlah kasus berasal dari sindikat internasional, baik sumber narkoba atau keterlibatan orang asing dalam peredaran narkoba (Baskoro, Rangga, 2019).

Berdasarkan data BNN Kabupaten Badung, pada tahun 2018 ditemukan sebanyak 34 kasus narkoba yang tersebar di 
beberapa kecamatan, seperti terlihat pada gambar 2 di bawah ini.

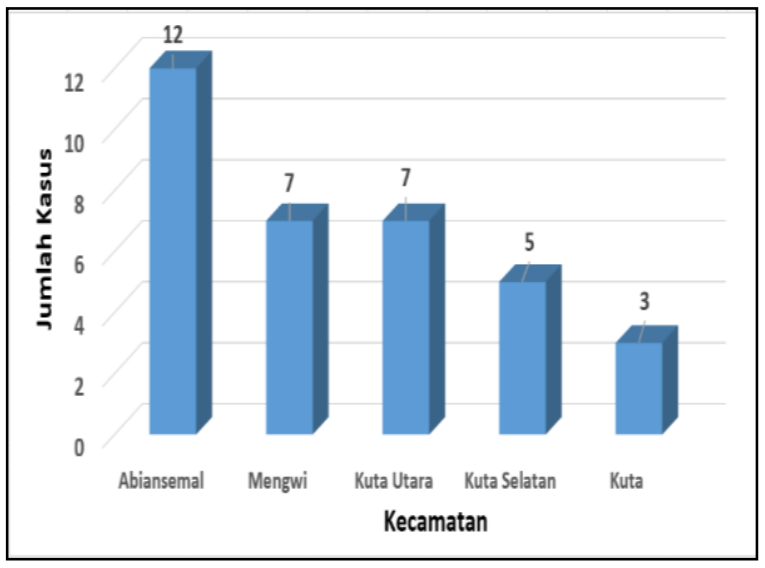

Gambar 2. Jumlah Kasus Narkoba di Kabupaten Badung Tahun 2018

Sumber: Diolah dari data BNN

Kabupaten Badung, 2018

Dari gambar 2 nampak bahwa kasus narkoba di Kabupaten Badung tidak hanya ditemukan di wilayah perkotaan tapi sudah menyebar sampai wilayah pedasaan. Bahkan diluar perkiraan, ternyata kasus narkoba justru terbanyak ditemukan di Kecamatan Abiansemal yang merupakan wilayah pedesaan di Kabupaten Badung. Demikian pula data publikasi BNN menyatakan bahwa saat ini ancaman narkoba tidak hanya menyerang perkotaan tetapi sudah merambah ke pedesaan. Dibuktikan dengan maraknya kasus narkoba di desa-desa seperti temuan lahan pertanian ganja dan sabu-sabu (Purbowianto, Tina. 2018).

Bedasarkan kelompok umur, data pecandu narkoba di Kabupaten Badung dapat dilihat pada gambar 3 di bawah ini.

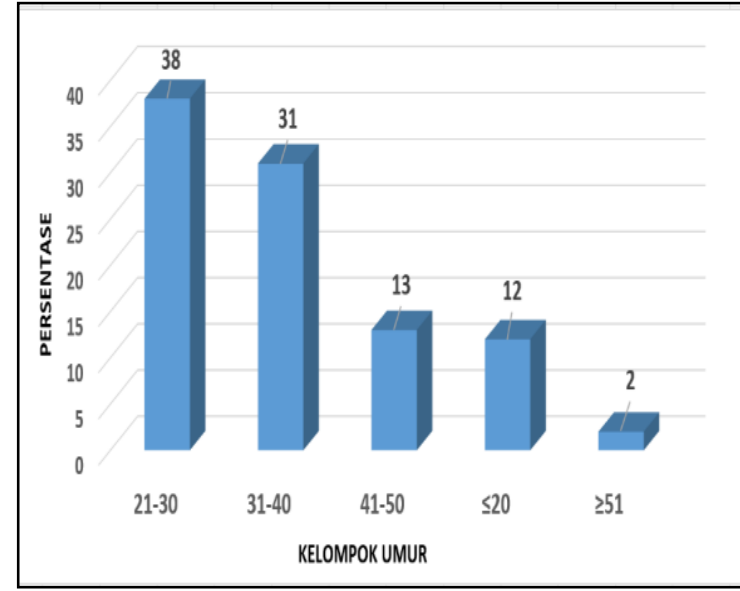

Gambar 3. Persentase Pecandu Narkoba di

Kabupaten Badung Tahun 2018

Sumber: Diolah dari data BNN

Kabupaten Badung, 2018

Gambar 3 memperlihatkan bahwa pecandu narkoba di Kabupaten Badung terbanyak adalah kelompok umur 21-30 tahun (38\%) yang merupakan usia produktif, lalu diikuti dengan kelompok umur 31-40 tahun (31\%) dan yang paling sedikit kelompok umur $\geq 50$ tahun. Data ini sesuai dengan data Badan Narkotika Nasional (BNN) Provinsi Bali yang mencatat bahwa jumlah penyalahguna narkoba di Pulau Dewata mencapai 2,01 persen dari jumlah penduduk atau sebanyak 61.353 jiwa. Mayoritas pengguna merupakan penduduk kelompok usia produktif yakni berusia 2140 tahun, sedangkan penyalahguna narkoba di luar usia produktif tidak mencapai satu persen (Mardika, Nyoman. 2017).

Jenis pekerjaan pecandu narkoba di Kabupaten Badung terbanyak bekerja sebagai karyawan swasta (57\%), berikutnya wiraswasta (14\%), yang terkecil mahasiswa/pelajar (8\%) dan pekerjaan lainlain (8\%). Untuk lebih jelasnya dapat dilihat pada Gambar 4. 


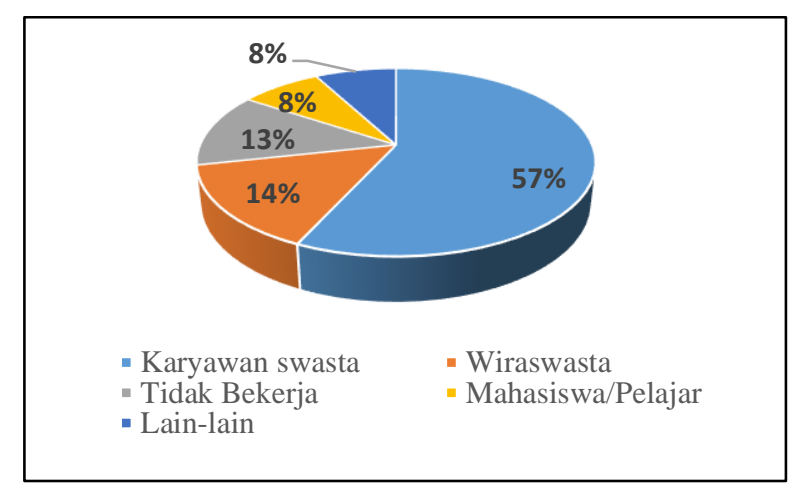

Gambar 4. Jumlah kasus Narkoba di Kabupaten Badung Tahun 2018

Sumber: Diolah dari data BNN Kabupaten Badung, 2018

Tingginya pengguna narkoba dari kalangan pekerja swasta dikarenakan tingginya tingkat stress akibat dari tekanan pekerjaan. Hal ini sesuai dengan hasil survei BNN tahun 2017 yang menyatakan bahwa proporsi penyalahguna narkoba terbesar adalah kelompok pekerja yaitu sebesar 59\%. Besarnya presentasi pekerja yang menggunakan narkoba dipicu oleh tekanan kerja dan tingkat stres yang tinggi dan ditambah dengan kemampuan finansial yang mandiri memudahkan mereka mendapatkan pasokan narkoba. Karyawan yang bekerja di beberapa bidang pekerjaan dengan tingkat stres tinggi memang lebih rentan terhadap paparan narkoba (Pertiwi, Putri, 2018).

Tingginya jumlah pecandu narkoba di Kabupaten Badung menuntut Pemerintah Kabupaten untuk segera tanggap terhadap ancaman narkoba. Terbitnya Instruksi Presiden Nomor 6 Tahun 2018 tentang Rencana Aksi Nasional Pencegahan dan Pemberantasan Penyalahgunaan dan Peredaran Gelap Narkotika dan Prekursor Narkotika Tahun 2018-2019, membuka peluang bagi Pemerintah Kabupaten Badung untuk menjalin kerjasama dengan Badan Narkotika Nasional Kabupaten Badun dalam upaya pencegahan dan pemberantasan penyalahgunaan dan peredaran gelap narkotika dan prekursor narkotika. Melalui kerjasama ini maka upaya pemberantasan narkoba di Kabupaten Badung akan berjalan lebih efektif, terarah dan terpadu.

Peluang lain dalam pencegahan dan pemberantasan narkoba di Kabupaten Badung adalah adanya dukungan dari Dinas Kesehatan dan Dinas Pendidikan, Pemuda dan Olahraga Kabupaten Badung. Di Jajaran kesehatan ada Rumah Sakit Daerah Mangusada, rumah sakit rujukan milik Pemerintah Daerah Kabupaten Badung, yang selalu siap melayani rujukan pasien pecandu narkoba. Demikian pula dengan UPT Puskesmas Kuta I, sejak tahun 2006 puskesmas ini sudah melaksanakan Program Terapi Rumatan Metadona (PTRM) yang memberikan layanan substitusi metadona khusus bagi pengguna narkotika heroin. ProgramTerapi Rumatan Methadone (PTRM) adalah program yang bertujuan membantu pecandu narkotika khususnya heroin untuk berhenti menggunakan atau mengurangi dampak buruk dari penggunaan alat suntik yang dapat menularkan penyakit HIV/AIDS.

Pada bidang pendidikan, mulai tahun 2016 implementasi kurikulum pendidikan sudah terintegrasi dengan program P4GN. Untuk jenjang pendidikan SMP, program P4GN terintegrasi dengan mata pelajaran Agama, IPS, Bhs Indonesia, PPKN \& Penjaskes, sedangkan untuk jenjang pendidikan SMA/SMK, program P4GN terintegrasi dengan mata pelajaran PPKN, Sejarah, Bhs Indonesia dan Penjaskes. Kurikulum terintegrasi P4GN merupakan kurikulum yang disisipkan atau diintegrasikan kedalam pembelajaran dan kurikulum P4GN bukanlah kurikulum yang berdiri sendiri. Implementasi kurikulum P4GN dalam pembelajaran di SMP dan SMA/SMK dilakukan dengan mengintegrasikan pembelajaran dengan memberi tambahan materi tentang 
penyalahgunaan narkoba kedalam proses pembelajaran (Suastawa, 2019).

Peran serta masyarakat Badung dalam mendukung upaya pemberantasan narkoba juga merupakan peluang tersendiri. Saat ini beberapa kelompok pecalang di lingkungan desa adat sudah dilatih dan dilantik oleh BNN Provinsi Bali sebagai relawan anti narkoba. Demikian pula pada tangkat desa, pada bulan Desember 2018 sebanyak 22 Desa Adat di Kabupaten Badung sudah menyusun Pararem (peraturan tertulis desa adat) dan dicanangan sebagai Desa Bersih Narkoba (Desa Bersinar) di Kabupaten Badung.

Relawan kelompok pecalang dan pararem desa adat ini akan menjadi garda terdepan dalam mengawal terwujudnya desa bersih narkoba di Kabupaten Badung, mengingat kedua komponen ini memiliki kewenangan dan posisi yang strategis dalam mengatur dan membina masyarakat melalui pendekatan adat/budaya di wilayahnya masing-masing.

Upaya dan komitmen Bupati Badung, Perangkat Daerah, lembaga terkait serta masyarakat di Kabupaten Badung dalam pencegahan pemberantasan penyalahgunaan dan peredaran gelap narkoba tergolong bagus. Hasil survey Indeks Kota Tanggap Ancaman Narkoba (Ikotan) tahun 2019 yang dilakukan oleh Pusat Studi Politik dan Keamanan (PSPK) Universitas Padjadjaran bekerja sama dengan BNN Pusat menempatkan Kabupaten Badung sebagai kabupaten/kota dengan Indeks Kota Tanggap Ancaman Narkoba (Ikotan) terbaik dengan nilai 82,10 (kategori Sangat Tanggap). Peringkat kedua dan ketiga ditempati oleh Kota Kediri (nilai 78,42) dan Kota Jakarta Timur (nilai 74,51) masingmasing dengan kategori Tanggap. Kriteria penilaian indeks meliputi aspek Ketahanan
Masyarakat, Kewilayahan, Kelembagaan, Hukum dan Ketahanan Keluarga.

Keberhasilan Kabupaten Badung memperoleh predikat terbaik Indeks Kota Tanggap Ancaman Narkoba merupakan suatu kebanggan. Namun demikian, tantangan dalam mewujudkan desa bersih narkoba di Kabupaten Badung cukup besar. Sebagai daerah destinasi wisata dengan jumlah tempat hiburan malam yang begitu banyak, Kabupaten Badung merupakan pangsa pasar yang potensial bagi perdagangan narkoba. Menurut BNN Pusat, Provinsi Bali masuk dalam 5 besar pengguna narkoba terbanyak di Indonesia, dan Kabupaten Badung merupakan daerah paling rawan narkoba di Provinsi Bali. Pada rasia pada bulan Agustus 2018 di kawasan Kuta, petugas BNN Kabupaten Badung beserta aparat terkait mengamankan seorang pengedar ekstasi (Pramana, Made. 2018). Demikian pula rasia bulan Agustus 2019 di beberapa cafe dan bar di wilayah kuta ditemukan 3 orang $(27 \%)$ dari 11 pengunjung cafe dan bar dinyatatakan positif memakai narkoba (Arifin, Zaenal Nur. 2019).

Tingginya permintaan narkoba mendorong pengedar untuk menjual narkoba di wilayah Kabupaten Badung. Salah satu cara untuk menekan permintaan narkoba adalah dengan merehabilitasi pengguna narkoba. Dengan menjalani rehabilitasi maka pengguna narkoba akan berangsurangsur pulih dan menghilangkan rasa candu terhadap narkoba. Keadaan seperti ini akan menekan permintaan narkoba sehingga peredaran dan pasokan narkoba juga akan mengalami penurunan (Putri, Maria Rosari. 2019).

Melaporkan keluarga atau warga yang pecandu narkoba agar mau menjalani rehabilitasi merupakan tantangan yang berat bagi BNN karena umumnya keluarga 
pecandu merasa takut adanya stigma dan sangsi adat untuk pecandu narkoba. Dengan telah dibangunnya pusat rehabilitasi narkoba di kabupaten Bangli diharapkan masyarakat Badung bersedia melaporkan keluarganya yang kecanduan narkoba untuk menjalani rehabilitasi di pusat rehabilitasi narkoba.

Melihat berbagai peluang dan tantangan, sangat besar kemungkinan untuk mewujudkan desa bersih narkoba di Kabupaten Badung. Kerjasama yang baik antara Pemerintah Kabupaten Badung dengan BNN Kabupaten Badung dan dukungan lembaga desa adat serta masyarakat badung akan modal sosial dalam mewujudkan desa bersih narkoba di Kabupaten Badung.

\section{SIMPULAN}

Kasus narkoba di Kabupaten Badung ada di kecamatan Kuta, Kuta Selatan, Kuta Utara, Mengwi dan Abiansemal. Pecandu narkoba paling banyak ditemukan pada pekerja swasta dan pengusaha, dengan kisaran umur antara 21 sampai dengan 30 tahun. Peluang dalam mewujudkan desa bersih narkoba adalah adanya kelompok pecalang dan adanya Pararem pencegahan pemberantasan penyalahgunaan narkoba. Sedangkan tantangan yang dihadapi adalah banyaknya tempat hiburan malam, munculnya stigma dan sangsi adat. Terkait dengan masalah tersebut di atas, pemerintah perlu melakukan pemetaan desa rawan narkoba dan pengembangan teknologi informasi untuk kerjasama dan koordinasi antar lembaga serta melakukan razia secara teratur pada tempat-tempat hiburan malam.

\section{DAFTAR PUSTAKA}

Haris, Agus, Setiyadi. (2019). BNN: Desa bersih narkoba dibentuk untuk perangi narkotika.

Diakses dari: https://www.antaranews.com/berita/826483/bnn-desa-bersih-narkobadibentuk-untuk-perangi-narkotika.

Arifin, Zaenal Nur. (2019). Razia Tempat Hiburan Malam di Denpasar-Kuta Ini Yang Ditemukan Petugas Pada Dini Hari.

Diakses dari: https://bali.tribunnews.com/2019/08/24/razia-tempat-hiburan-malam-didenpasar-kuta-ini-yang-ditemukan-petugas-pada-dini-hari.

Baskoro, Rangga. (2019). BNN Ungkap Rencana untuk Mencegah Masuknya Peredaran Narkoba Melalui Perbatasan Negara. Diakses dari: https://wartakota.tribunnews.com/2019/07/23/bnn-ungkap-rencana-untukmencegah-masuknya-peredaran-narkoba-melalui-perbatasan-negara.

Dhalyana, Dini, dkk. (2013). Pengaruh Taman Wisata Alam Pangandaran Terhadap Kondisi Sosial Ekonomi Masyarakat, Sodality: Jurnal Sosiologi Pedesaan | Desember 2013, hlm: 182-199, Diakses dari: file:///9402-26874-2-PB.pdf. Iskan, Dahlan. (2019). Revolusi Wanita. https://web.facebook.com/ permalink. php?story fbid= $2348463598600875 \& \mathrm{id}=249878121792777 \&$ tn $=\mathrm{K}-\mathrm{R}$.

Mardika, Nyoman. (2017). Jumlah Pecandu Narkoba di Bali Capai 61.353 Jiwa. Diakses dari: $\quad$ https://www.beritasatu.com/nasional/409077/jumlah-pecandu-narkoba-dibali-capai-61353-jiwa.

Manurung., Heliany., (2019). Peran Pemerintah Kota Tanggerang Selatan Dan Universitas Muhammadiyah Jakarta Dalam Mengurangi Peredaran Narkoba Melalui Konsep 
Smart City. Seminar Nasional Pengabdian Masyarakat Universitas Muhammadiyah Jakarta, 24 September 2019

Purbowianto, Tina. (2018). Pedesaan di Indonesia Menjadi Target Narkoba. Diakses dari: https://www.kompasiana.com/tinapurbo/5c13c57ebde5754df0003f75/pedesaandi-indonesia-menjadi-target-narkoba?page $=$ all.

Padmohoedojo, Paulina. (2014). Peran Masyarakat Dibutuhkan dalam Mencegah Penyalahgunaan Narkoba. Diakses dari: https://news.okezone.com/read/2014/09/20/542/1041935/peran-masyarakatdibutuhkan-dalam-mencegah-penyalahgunaan-narkoba.

Peraturan Daerah Kabupaten Badung Nomor 24 Tahun 2013 Tentang Pengelolaan Rumah Kos.

Putri, Maria Rosari. 2019. Upaya menekan permintaan narkoba. Diakses dari: https://www.antaranews.com/berita /794598/ upaya- menekan- permintaannarkoba.

Pramana, Made. 2018. Razia Tempat Hiburan Malam di Bali, Petugas Amankan Seorang Bandar Ekstasi. Diakses dari: http://rri.co.id/post/berita/560579/sigap_polri/razia_tempat_hiburan_malam_di_ba li_petugas_amankan_seorang_bandar_ekstasi.html.

Pertiwi, Putri .2018. Porsi Terbesar Penyalahguna Narkoba Adalah Karyawan! Ini Hal Yang Perlu Perusahaan Lakukan. Diakses dari: https://integrityindonesia.com/id/blog/2018/11/07/ porsi-terbesar-penyalahguna-narkoba-adalahkaryawan-ini-hal-yang-perlu-perusahaan-lakukan/.

Pina, Soedirham, 2015, Dukungan Pemerintah Dalam Mencegah Penyalahgunaan Narkoba Di Kota Surabaya. Jurnal Promkes, Vol. 3, No. 2 Desember 2015: 171182. Diakses dari: https://ejournal.unair.ac.id/index.php/PROMKES/article/viewFile/4465/3026.

Suastawa, Putu Gede, 2019, Pola Perkembangan Kejahatan Narkoba Di Bali, Materi Seminar Nasional Indeks Kota/Kab. Tanggap Anca, ancaman Narkoba. Badan Narkotika Nasional Provinsi Bali.

Haris, Agus, Setiyadi. (2019). BNN: Desa bersih narkoba dibentuk untuk perangi narkotika. https://www.antaranews.com/berita/826483/bnn-desa-bersih-narkobadibentuk-untuk-perangi-narkotika. Diakses pada tanggal 26 Agustus 2019.

Arifin, Zaenal Nur. (2019). Razia Tempat Hiburan Malam di Denpasar-Kuta Ini Yang Ditemukan Petugas Pada Dini Hari. https://bali.tribunnews.com/2019/08/24/raziatempat-hiburan-malam-di-denpasar-kuta-ini-yang-ditemukan-petugas-pada-dinihari. Diakses pada tanggal 26 Agustus 2019.

Baskoro, Rangga. (2019). BNN Ungkap Rencana untuk Mencegah Masuknya Peredaran Narkoba Melalui Perbatasan Negara, https://wartakota.tribunnews.com/2019/07/23/bnn-ungkap-rencana-untukmencegah-masuknya-peredaran-narkoba-melalui-perbatasan-negara. Diakses pada tanggal 25 Agustus 2019.

Dhalyana, Dini, dkk. (2013). Pengaruh Taman Wisata Alam Pangandaran Terhadap Kondisi Sosial Ekonomi Masyarakat, Sodality: Jurnal Sosiologi Pedesaan | Desember 2013, hlm: 182-199, file://C:/Users/BALITBANG-06/Downloads/9402-26874-2PB.pdf. Diakses pada tanggal 25 Agustus 2019. 
Iskan, Dahlan. (2019). Revolusi Wanita. https://web.facebook.com/ permalink. php?story_fbid $=\quad 2348463598600875 \& \mathrm{id}=249878121792777 \&$ tn $\_=\mathrm{K}-\mathrm{R}$. Diakses pada tanggal 24 Agustus 2019.

Mardika, Nyoman. (2017). Jumlah Pecandu Narkoba di Bali Capai 61.353 Jiwa. https://www.beritasatu.com/nasional/409077/jumlah-pecandu-narkoba-di-balicapai-61353-jiwa. Diakses pada tanggal 25 Agustus 2019.

Purbowianto, Tina. (2018). Pedesaan di Indonesia Menjadi Target Narkoba. https://www.kompasiana.com/tinapurbo/5c13c57ebde5754df0003f75/pedesaandi-indonesia-menjadi-target-narkoba?page=all. Diakses pada tanggal 25 Agustus 2019.

Padmohoedojo, Paulina. (2014. Peran Masyarakat Dibutuhkan dalam Mencegah Penyalahgunaan Narkoba. https://news.okezone.com/read/2014/09/20/542/1041935/peran-masyarakatdibutuhkan-dalam-mencegah-penyalahgunaan-narkoba. Diakses pada tanggal 23 Agustus 2019.

Peraturan Daerah Kabupaten Badung Nomor 24 Tahun 2013 Tentang Pengelolaan Rumah Kos.

13. Putri, Maria Rosari. 2019. Upaya menekan permintaan narkoba. https://www.antaranews.com/berita /794598/ upaya- menekan- permintaannarkoba. Diakses pada tanggal 26 Agustus 2019.

Pramana, Made. 2018. Razia Tempat Hiburan Malam di Bali, Petugas Amankan Seorang Bandar

Ekstasi.http://rri.co.id/post/berita/560579/sigap_polri/razia_tempat_hiburan_mala m_di_bali_petugas_amankan_ seorang_bandar_ekstasi.html. Diakses pada tanggal 26 Agustus 2019.

Pertiwi, Putri . 2018. Porsi Terbesar Penyalahguna Narkoba Adalah Karyawan! Ini Hal Yang Perlu Perusahaan Lakukan. https://integrity-indonesia.com/id/blog/2018/11/07/ porsi-terbesar-penyalahguna-narkoba-adalah-karyawan-ini-hal-yang-perluperusahaan-lakukan/. Diakses pada tanggal 25 Agustus 2019.

Suastawa, Putu Gede, 2019, Pola Perkembangan Kejahatan Narkoba Di Bali, Materi Seminar Nasional Indeks Kota/Kab. Tanggap Anca, ancaman Narkoba. Badan Narkotika Nasional Provinsi Bali. 